\title{
Using fuzzy logic approach to predict work-related musculoskeletal disorders among automotive assembly workers
}

\author{
Mohsen Falahati ${ }^{1}$, Fatemeh Dehghani ${ }^{2}$, Mahdi Malakoutikhah ${ }^{3}$, Ali Karimi*3, ${ }^{*}$ Asma Zare ${ }^{3}$, Saeed Yazdani rad ${ }^{4}$
}

Received: 3 Nov 2018

Published: 16 Dec 2019

\section{Abstract}

Background: Musculoskeletal disorders (MSDs) are considered an important health concern, particularly in automotive assembly industries. Evaluation of the effects of all MSDs risk factors is difficult due to its multifactorial nature. In addition, the risk factors cannot be detected accurately when they are only based on individual opinions. Thus, in this study, fuzzy logic tool was used to evaluate the combined effects of all risk factors on MSDs.

Methods: This cross sectional study was conducted on 100 male workers in an automotive industry. Job satisfaction, job stress, job fatigue, and body posture were evaluated by a self-reported questionnaire. Body posture was evaluated using Rapid Entire Body Assessment (REBA). Primary data analysis on extracting the input variables of MATLAB was performed by SPSS 22, with a significant level of 0.05 . T test, one-way Anova, and Pearson correlation analysis were used to extract the input variables for the fuzzy logic model. The results obtained from the Nordic questionnaire was selected as the output of the fuzzy model. Fuzzy logic assessment was performed using MATLAB software version 7.0.

Results: There were significant differences between WMSDs factors, including job fatigue, strain, working posture, and the REBA final score, and pain in all limbs of the body $(\mathrm{p}<0.05)$. A significant difference was also found between working posture with wrist score $(\mathrm{p}<0.05)$. The findings on defuzzification showed a strong correlation between real and modelling results.

Conclusion: The results showed that many factors such as posture, fatigue, and strain affect MSDs. Based on the obtained results, all categories of risk factors, including personal, psychosocial, and occupational, should be considered to predict MSDs, which can be achieved by a modeling approach.

Keywords: Fuzzy logic, Work-related musculoskeletal disorders, Automotive industry

Conflicts of Interest: None declared

Funding: Tehran University of Medical Sciences.

\section{*This work has been published under CC BY-NC-SA 1.0 license.}

Copyright $($ Iran University of Medical Sciences

Cite this article as: Falahati M, Dehghani F, Malakoutikhah M, Karimi A, Zare A, Yazdani rad S. Using fuzzy logic approach to predict work-related musculoskeletal disorders among automotive assembly workers. Med J Islam Repub Iran. 2019 (16 Dec);33:136. https://doi.org/10.47176/mjiri.33.136

\section{Introduction}

Assembly line is a main process in manufacturing industries where different parts are consecutively assembled to make the final product. The automotive assembly industry

\footnotetext{
Corresponding author:Dr Ali Karimi, a_karimi@sina.tums.ac.ir

1. Social Determinants of Health Research Center, Saveh University of Medical Sciences, Saveh, Iran

2. Research Center for Health Sciences, Institute of Health, Department of Occupational Health Engineering, School of Health, Shiraz University of Medical Sciences, Shiraz, Iran

3. Department of Occupational Health, School of Public Health, Tehran University of Medical Sciences, Tehran, Iran.

4. School of Health, Shahrekord University of Medical Sciences, Shahrekord, Iran
}

is an example of industry with different assembly processes. Highly repetitive tasks, short work cycles, shift work, and use of manpower have led to workers being exposed to numerous harmful agents, especially ergonomic

$\uparrow$ What is "already known" in this topic:

Musculoskeletal disorders (MSDs), as a multifactorial health problem, arise from inappropriate ergonomic conditions. Posture of workers has been found to be a main risk factor for MSDs in many previous studies. Different methods have been used to find the relationship between work conditions and MSDs.

\section{$\rightarrow$ What this article adds:}

The association between the strain and stress risk factors (awkward posture as a stress risk factor, working fatigue as a strain factor, and MSD as their consequence) was examined in the present study. 
hazards (1). Musculoskeletal disorders (MSDs) are a common health problem arising from inappropriate ergonomic conditions. The Bureau of Labor Statistics in the United States (US) indicated that MSDs are responsible for $29 \%$ $35 \%$ of all occupational injuries and illnesses worldwide (2). The annual direct and indirect cost of MSDs to the Canadian economy was estimated to be around \$20 billion (3). However, the statistics on MSDs and their subsequent outcome are more striking in developing countries like Iran (4). Almost 14000 workers are employed in the automobile industries in Iran (5). Awkward and sedentary postures, standing for a long time, repetitive movements along with other personal, environmental, and psychological factors are associated with increased work-related musculoskeletal disorders (6). Many studies have been conducted to evaluate the effects of the mentioned factors on prevalence of MSDs (6-10). The results of a study on truck assembly workers, demonstrated that almost $79 \%$ of the workers are at risk of MSDs. Low back pain, with an incidence of $65 \%$, was reported as the most prevalent musculoskeletal symptom (2). The role of awkward posture, as a main risk factor for MSDs, was evaluated in the study conducted on automotive factory workers in Malaysia (11). The relationship between workload and MSDs with age was also evaluated (12). The multifactorial nature of MSDs makes them difficult for analysis. Expert systems, decision support systems, and integrated systems are 3 probabilitybased systems used for problem-solving analysis. Fuzzy logic is a linear model used to compute the outcome based on degree of truth rather than true or false (0 and 1) (13). Many studies have evaluated the effect of different risk factors on MSDs using modelling approach. For example, an adaptive neuro-fuzzy inference method was used to predict the risks of low back pain in manual material lifting activities (14). A fuzzy neural network method was applied to classify the risk of low back disorders (15). Another study worked on low back pain in manual material handling using fuzzy logic method (16). Even though many studies have been performed to find the relationship between risk factors and MSDs among automotive assembly line workers, the associations of awkward posture as a stress risk factor, working fatigue as a strain factor, and MSD as the consequence have not yet been clearly stated by modelling. Thus, the present study was conducted to predict MSDs based on fatigue and postural factors among automotive assembly line workers.

\section{Methods}

\section{Study design and data collection}

This cross sectional study was conducted on 110 male workers in an auto assembly industry. The inclusion criteria were no experience of chronic low back pain, accident, or back surgery. Several graduate students of occupational ergonomics collected data using a 4-section questionnaire.

The first section of the questionnaire was used to collect the demographic information, including age, height, weight, work experience, number of working hours in a day and week, daily rest periods, duration of exercise time per week, accident, work experience, and work location.

\section{Strain evaluation}

Job satisfaction and job stress as the main strain factors were evaluated by a 10-point Likert scale, ranging from (dissatisfied and full of stress) to 10 (absolutely stress-free and completely satisfied).

\section{Posture evaluation}

Working posture was evaluated in the third part of the questionnaire by a 10-level scale, which included 6 items: handling, bent waist, repetitive movement, hand and arm movements, prolonged sitting or standing, and moving hands away from the body. In addition to self-reported assessment, the Rapid Entire Body Assessment method (REBA) was used to evaluate body posture (17). The final score of REBA was calculated to be between 1 to 15 based on the scores obtained from evaluating different parts of the body (18).

\section{Fatigue evaluation}

The last part of the questionnaire was focused on fatigue assessment using the 20-item Swedish Fatigue Questionnaire (SOFI), which includes questions about lack of energy, physical effort, physical discomfort, lack of motivation, and sleepiness. All questions are rated using an 11degree Likert scale from zero (totally disagree) to 10 (completely agreement). The Persian version of this questionnaire has been found to have sufficient reliability and validity (19).

Statistical analysis was performed by SPSS version 22.0 to identify the main input variables for fuzzy logic method. Student $t$ test and one-way ANOVA were used to compare a variable in 2 or more than 2 groups, respectively. Pearson correlation analysis was used to determine the relationship between variables.

\section{WMSDs symptom evaluation}

The standardized Nordic questionnaire was used to study the prevalence of MSDs symptoms in different parts of the body. The participants were asked if they had pain or discomfort in different limbs of the body during the 12 previous months. They were also asked to specify the severity of the pain by scoring it from 0 to 10 . The Persian version of the questionnaire has been found to be valid and reliable (20).

\section{Fuzzy logic}

Fuzzy logic is a mathematical tool to predict unknown and multifactorial issues (21). The main difference between fuzzy expert systems with conventional expert systems is the presence of numerical processing instead of the symbolic reasoning engines (22). A fuzzy set is a group of objects with a continuum of grades of the membership. This set is characterized by a membership (characteristic) function that operates over the range of real numbers $[0,1](23)$. Characteristics of the fuzzy inference system is presented in Table 1. The REBA final score, fatigue, and strain were considered as the input variables for fuzzy modelling. The input and output variables were converted into the linguistic variables. Each variable was divided into 4 categories. Categories and fuzzy numbers are shown in Table 2. The 


\begin{tabular}{|c|c|c|c|}
\hline Operation & Operator & Role & Formula \\
\hline SUM (OR) & MAX & T-conorm & $\mu C(x)=\max (\mu A(x), \mu B(x))=\mu A(x) \vee \mu B(x)$ \\
\hline Subscription (AND) & MIN & T-norm & $\mu C(x)=\min (\mu A(x), \mu B(x))=\mu A(x) \wedge \mu B(x)$ \\
\hline Implication & MIN & T-norm & $\max (\min (\mu A(x), \mu B(x)))$ \\
\hline Aggregation & MAX & T-conorm & \\
\hline Defuzzification & Center & & $C O A=z=\frac{\int z \mu(z) d z}{\int \mu(z) d z}$ \\
\hline
\end{tabular}

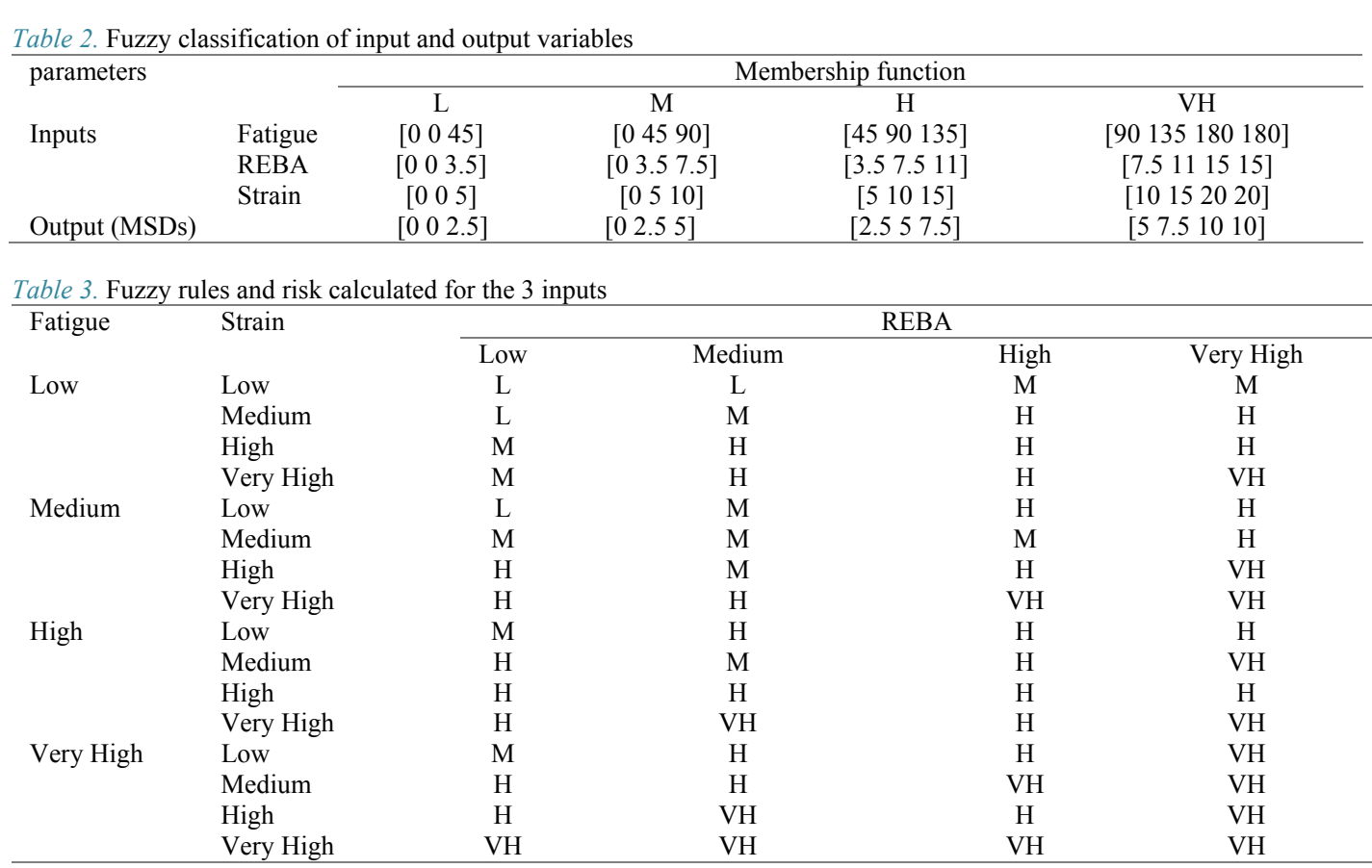

membership degree of any variable specified in a triangular or trapezoidal state and the fuzzy diagram were plotted in the MATLAB software. Nordic questionnaire variables were designed as a trapezoidal shape and other variables as triangular-shaped.

The rules related to 3-phase fuzzy functions are presented in Table 3. The sum of the numbers obtained from stress and job satisfaction were resulted in the strain number as the following equation: Strain $=$ Stress $+(10$ - Satisfaction $)$.

\section{Results}

The means (SD) of age and work experience were 34.41 (6.14) and 8.68 (5.25) years, respectively. The means of working and rest hours per day were 10.21 and 6.42 , respectively. A general pattern of fuzzy system, the linguistic variables for each input and output, and the relationship between inputs and outputs are shown in Figures 1, 2, and 3, respectively. The presented data in Table 4 indicate no significant relationship between demographic information and

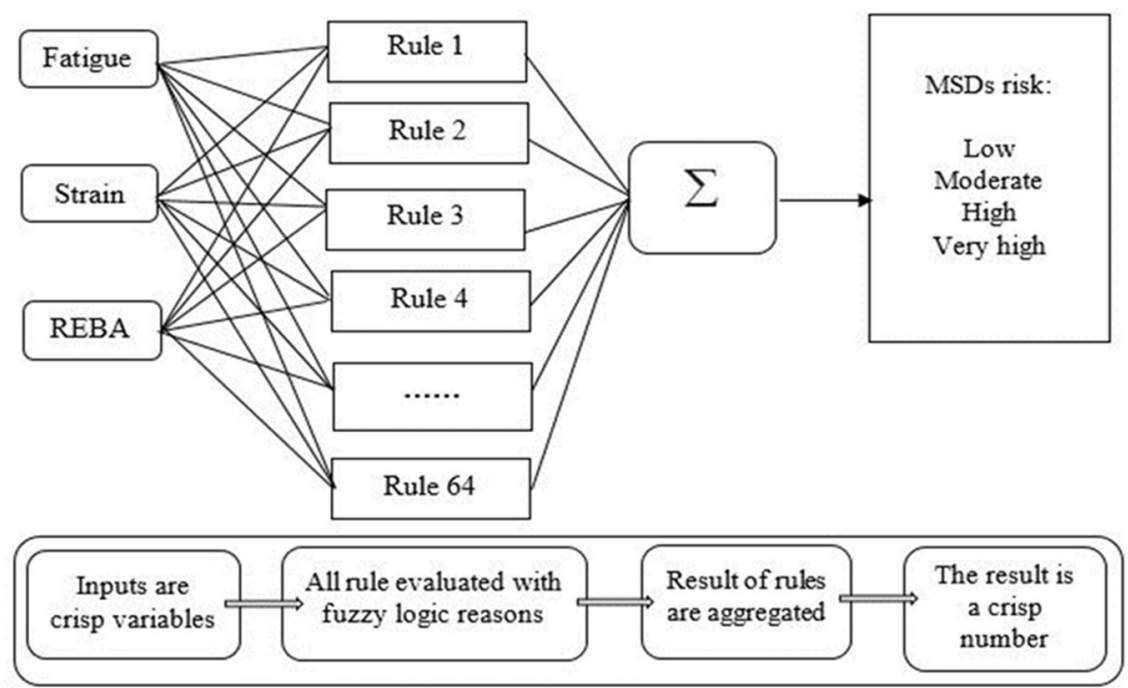

Fig. 1. The general pattern of the fuzzy system 


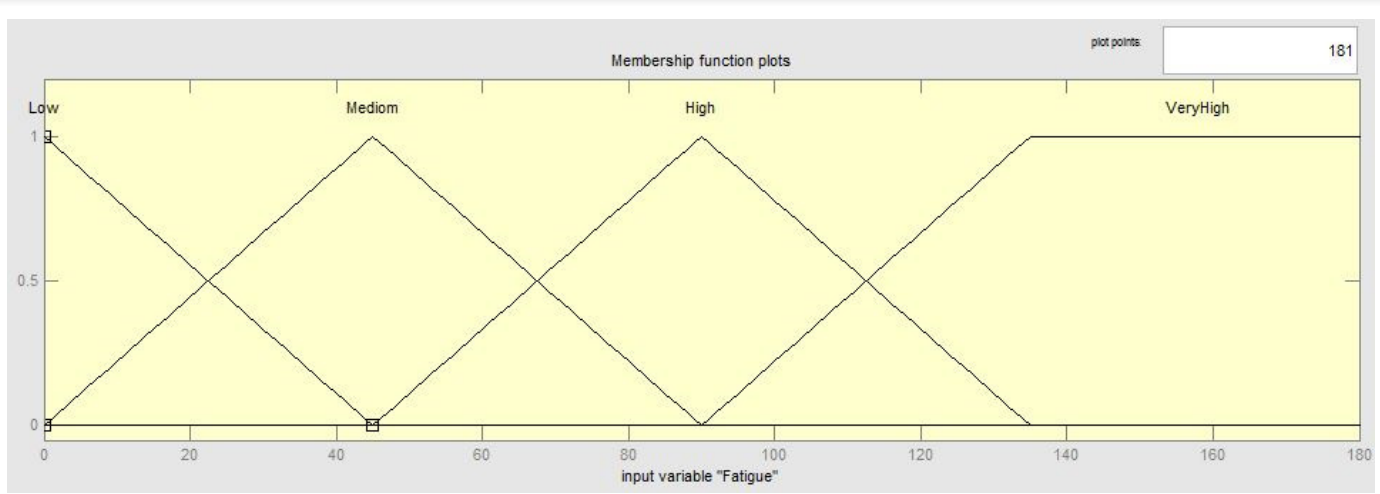

A

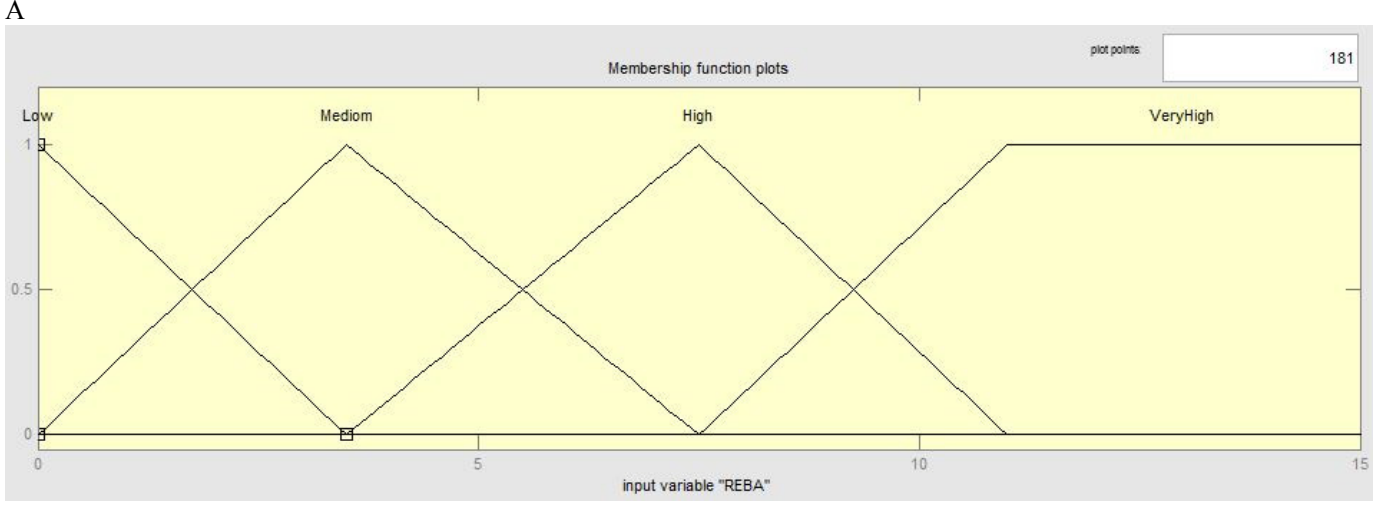

B

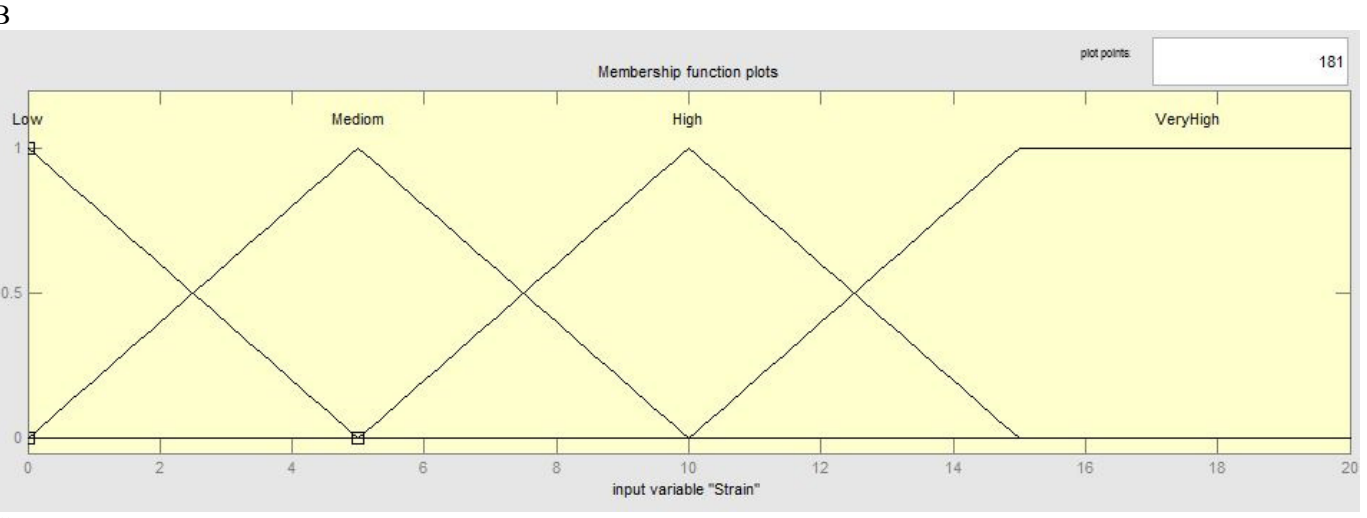

$\mathrm{C}$

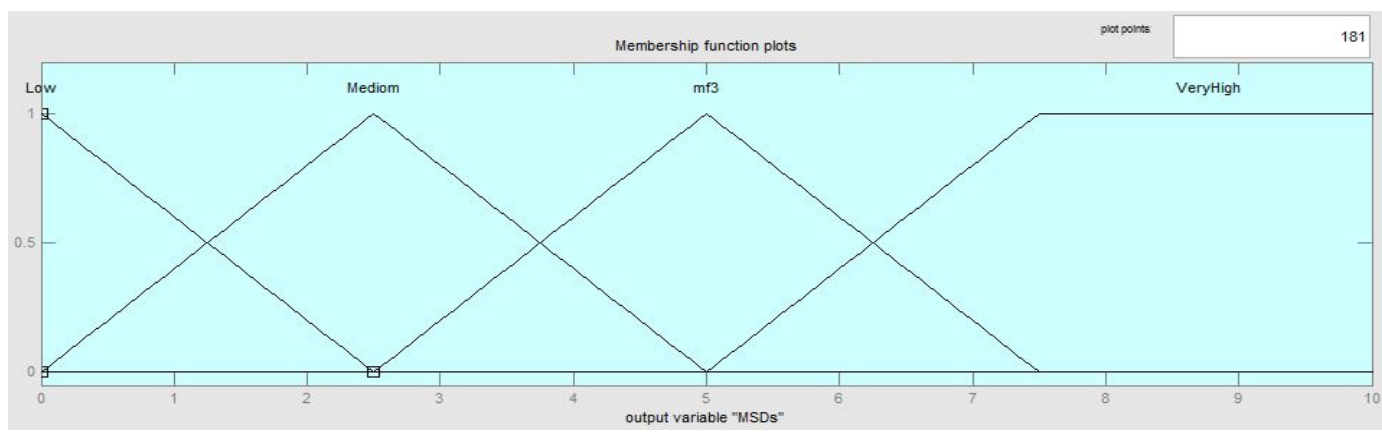

D

Fig. 2. The linguistic variables for each input and output on fuzzy logic. A: linguistic variables of job strain, B: linguistic variables of REBA, C: linguistic variables of strain and D: The output linguistic variables of musculoskeletal disorders.

MSDs in at least one limb.

The results obtained from the one-way ANOWA analysis are presented in Table 5. The results imply that strain, working posture, and REBA final scores were significant in all of the 9 limbs of the body. There was a nonsignificant relationship between fatigue assessment and some of the subscales of the Nordic questionnaire. Also, a significant relationship was found between the postural factor and the wrist score obtained from the NORDIC questionnaire.

Fatigue and REBA final scores were the input variables for neck, shoulders, upper back, elbows, and lower back, and the stain score was added as an input variable for wrists assessment (Table 5).

The correlation between defuzzification results and the 


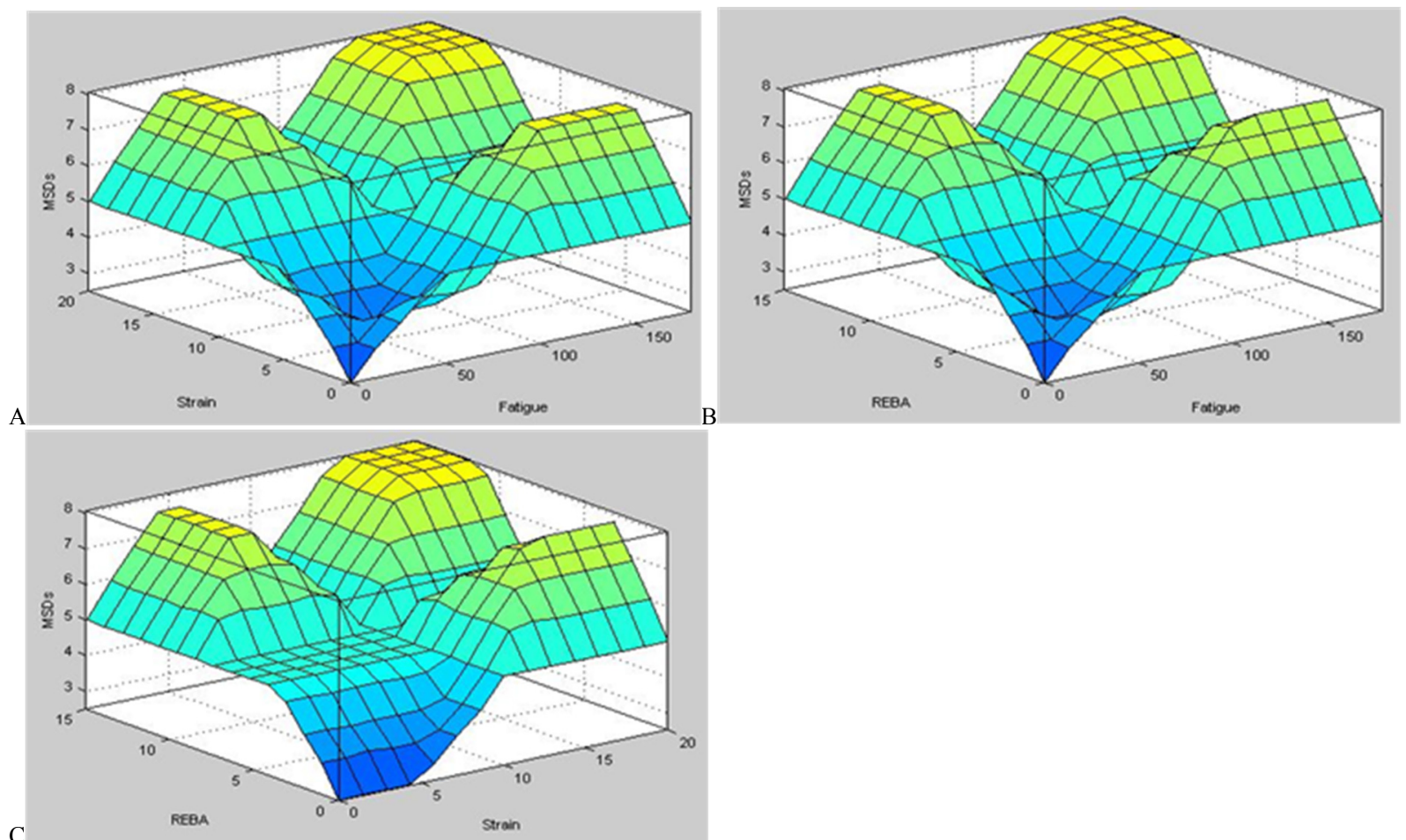

Fig. 3. A 3-dimensional view and relationship between inputs and outputs taking into account the laws. Output: musculoskeletal disorders and inputs: A: fatigue and stress figure, B: fatigue and final score of REBA and C: job stress and final score of REBA.

Table 4. Demographic variables in the 2 groups (with and without any disorders) and their differences

\begin{tabular}{|c|c|c|c|c|}
\hline \multirow{2}{*}{\multicolumn{2}{|c|}{ Demographic information }} & \multirow{2}{*}{\multicolumn{2}{|c|}{ Musculoskeletal disorders }} & \multirow[t]{3}{*}{$\mathrm{p}$} \\
\hline & & & & \\
\hline \multirow{3}{*}{ Age } & & & & \\
\hline & Less than 30 years & $27(27.8)$ & $2(40)$ & 0.561 \\
\hline & More than 30 years & $70(72.2)$ & $3(60)$ & \\
\hline \multirow[t]{2}{*}{ Working experience } & Less than 10 years & $59(62.8)$ & $3(75)$ & 0.623 \\
\hline & More than 10 years & $35(37.2)$ & $1(25)$ & \\
\hline \multirow[t]{2}{*}{ Working hours } & Less than 10 hours & $63(64.9)$ & $3(75)$ & 0.801 \\
\hline & More than 10 hours & $34(35.1)$ & $1(25)$ & \\
\hline \multirow[t]{2}{*}{ Rest hours } & Less than 6 hours & $55(56.7)$ & $2(40)$ & 0.171 \\
\hline & More than 6 hours & $42(43.3)$ & $3(60)$ & \\
\hline Total & & $97(100)$ & $5(100)$ & \\
\hline
\end{tabular}

Table 5. The difference of WMSDs variables in different parts of the body ( $\mathrm{P}$ value)

\begin{tabular}{|c|c|c|c|c|c|c|c|c|c|}
\hline Parts of Body & $\begin{array}{l}\text { Lack of } \\
\text { Energy }\end{array}$ & $\begin{array}{l}\text { Physical } \\
\text { Effort }\end{array}$ & $\begin{array}{l}\text { Physical } \\
\text { Discomfort }\end{array}$ & $\begin{array}{c}\text { Lack of } \\
\text { Motivation }\end{array}$ & Sleepiness & $\begin{array}{c}\text { Total } \\
\text { Fatigue }\end{array}$ & Strain & $\begin{array}{l}\text { Work } \\
\text { Posture }\end{array}$ & $\begin{array}{l}\text { REBA } \\
\text { Score }\end{array}$ \\
\hline Neck & 0.184 & 0.052 & 0.035 & 0.103 & 0.106 & 0.030 & 0.042 & 0.838 & 0.661 \\
\hline Shoulder & 0.020 & 0.012 & $<0.001$ & 0.006 & 0.002 & $<0.001$ & 0.768 & 0.363 & 0.602 \\
\hline Upper Limb & 0.119 & 0.037 & 0.049 & 0.002 & 0.059 & 0.043 & 0.181 & 0.079 & 0.018 \\
\hline Elbow & 0.010 & 0.003 & $<0.001$ & 0.012 & 0.004 & $<0.001$ & 0.364 & 0.464 & 0.264 \\
\hline Lower Limb & 0.065 & 0.376 & $<0.001$ & 0.140 & 0.066 & 0.044 & 0.048 & 0.480 & 0.822 \\
\hline Wrist & 0.010 & $<0.001$ & $<0.001$ & 0.059 & 0.034 & 0.002 & 0.934 & 0.037 & 0.012 \\
\hline Hip and Leg & 0.005 & 0.013 & $<0.001$ & $<0.001$ & 0.025 & $<0.001$ & 0.778 & 0.844 & 0.921 \\
\hline Knee & 0.019 & 0.001 & $<0.001$ & $<0.001$ & 0.001 & $<0.001$ & 0.722 & 0.209 & 0.727 \\
\hline Feet & 0.003 & 0.032 & $<0.001$ & $<0.001$ & 0.001 & $<0.001$ & 0.213 & 0.061 & 0.140 \\
\hline
\end{tabular}

actual scores obtained from the Nordic questionnaire was evaluated using SPSS. Transformation of the fuzzy results into a precise output by MATLAB software is called defuzzification. Table 6 shows the correlation between the number of fuzzy logic and actual numbers in every part of the body. Also, the relationship between actual and fuzzy numbers are shown in Figure 4.

\section{Discussion}

This study was conducted to predict work-related musculoskeletal disorders among automotive assembly workers. The results revealed that various factors, including posture, fatigue, and strain, affect the incidence of musculoskeletal disorders. However, no significant relationship was obtained between demographic variables and musculoskeletal disorders.

Body posture is one of the most important risk factors for MSDs, and thus has been considered as an input variable 


\begin{tabular}{lcc} 
Table 6. The Pearson correlation coefficient between the defuzzification numbers and real numbers separated by parts of the body \\
\hline Parts of body & $\mathrm{p}$ & $\mathrm{R}$ \\
\hline Neck & $<0.001$ & 0.265 \\
Shoulder & $<0.001$ & 0.347 \\
Upper Limb & $<0.001$ & 0.474 \\
Elbow & $<0.001$ & 0.335 \\
Lower Limb & $<0.001$ & 0.221 \\
Wrist & $<0.001$ & 0.327 \\
\hline
\end{tabular}



A



$\mathrm{C}$

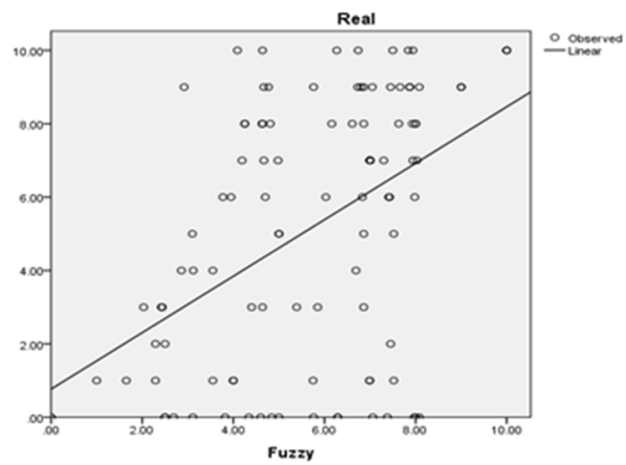



B

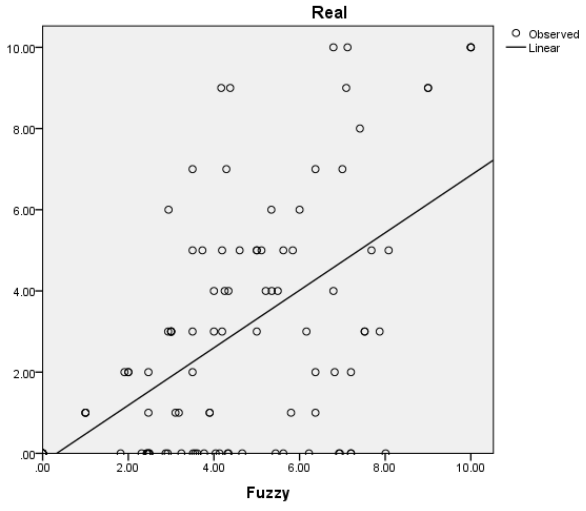

$\mathrm{D}$

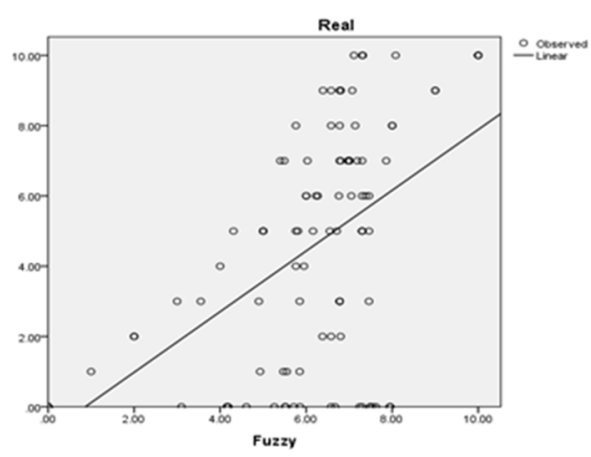

$\mathrm{F}$

Fig. 4. It demonstrates the relationship between actual and numbers modeled. A: Correlation between actual and fuzzy numbers in neck, B: Correlation between actual and fuzzy numbers in shoulder, C: Correlation between actual and fuzzy numbers in shoulder upper back, D: Correlation between actual and fuzzy numbers in elbow, E: Correlation between actual and fuzzy numbers in shoulder lower back, F: Correlation between actual and fuzzy numbers in wrist.

for modeling regardless of any significant relationship with the NORDIC scores. The proposed model was also presented only for the upper part of the body because of particular importance of upper libs of the body in assembly work. Also, the results showed a significant correlation between fatigue and MSDs. Among all of the risk factors, only fatigue score had a strong correlation with MSDs in all parts of the body. The results indicated that the probability of discomfort and MSDs is increased under postural and physiological stress. The results clearly showed that MSDs increased when body resistance was reduced due to




fatigue, which is consistent with other studies (7). Therefore, it is highly important to consider strain factors such as job stress and job satisfaction as the main input variables for MSDs assessment. The strain and posture parameters, as work-related mental and physical factors, had an effect on musculoskeletal disorders. Increased mental workload can decease comfort and physical endurance, making the individual susceptible to MSDs (8). Awkward posture can cause MSDs, as it increases the pressure on different parts of the body (9).

The results showed that posture assessment is not enough to assess MSDs and other factors such as fatigue and strain should be considered for evaluation.

The findings related to defuzzification of the fuzzy model illustrated a strong correlation between real and modelling numbers. Therefore, all risk factors, including personal and psychosocial factors, should be considered simultaneously with occupational factors to predict musculoskeletal disorders and to develop effective potential intervention actions. In addition, a predictive model based on the fuzzy logic can effectively deal with the existing uncertainty in the system and the large amount of data required. Various studies have been performed to predict different disorders in workers. For example, Gulbandilar et al used fuzzy logic algorithm to predict back pain and found that the fuzzy logic method can assess the problem accurately (24). Also, in 2015, Golabchi et al used the fuzzy logic model for ergonomic analysis in construction industry. They compared the obtained results of the fuzzy logic model with biomechanical analysis and found that the model provides more accurate results than traditional methods, and thus reduces human errors $(2$, 25).

\section{Conclusion}

Controlling MSDs depends on identifying and evaluating all risk factors related to MSDs. In the present study, a new approach was proposed to evaluate MSDs. The high correlation between the factors makes analysis difficult; thus, analysis should be done by a modeling tool to evaluate the correlation between all variables. The results of the present study showed that the fuzzy logic model is a reliable tool to determine MSDs.

\section{Acknowledgements}

The authors appreciate the participants of this study for their time and cooperation.

\section{Conflict of Interests}

The authors declare that they have no competing interests.

\section{References}

1. Zamanian Z, Mohammadi H, Rezaeeyani M, Dehghany M. An investigation of shift work disorders in security personnel of 3 hospitals of Shiraz University of Medical Sciences, 2009. IR Occup Health. 2012;9(1):52-7.

2. Bhattacharya A. Costs of occupational musculoskeletal disorders (MSDs) in the United States. Int J Ind Ergon. 2014;44(3):448-54.

3. Golabchi A, Han S, Fayek AR. A fuzzy logic approach to posturebased ergonomic analysis for field observation and assessment of construction manual operations. Can J Civ Eng. 2016;43(4):294-303.
4. Zamanian Z, Nikravesh A, Monazzam MR, Hassanzadeh J, Fararouei M. Short-term exposure with vibration and its effect on attention. J Environ Health Sci Eng. 2014;12(1):135.

5. Golbabaei F, Dehghani F, Saatchi M, Zakerian SA. Evaluation of occupational exposure to different levels of mixed organic solvents and cognitive function in the painting unit of an automotive industry. Health Promot Perspect. 2018;8(4):296.

6. Nahin RL, Barnes PM, Stussman BJ. Expenditures on complementary health approaches: United States, 2012. 2016.

7. Widanarko B, Legg S, Devereux J, Stevenson M. The combined effect of physical, psychosocial/organisational and/or environmental risk factors on the presence of work-related musculoskeletal symptoms and its consequences. Appl Ergon. 2014;45(6):1610-21.

8. Kee D, Karwowski W. A comparison of three observational techniques for assessing postural loads in industry. Int J Occup Saf Ergon. 2007;13(1):3-14.

9. Palmer KT, Goodson N. Ageing, musculoskeletal health and work. Best practice \& research Clinical rheumatology. 2015;29(3):391-404.

10. Govindu NK, Babski-Reeves K. Effects of personal, psychosocial and occupational factors on low back pain severity in workers. Int $\mathrm{J}$ Ind Ergon. 2014;44(2):335-41.

11. Yazdani A. Association between ergonomic risk factors and musculoskeletal symptom among automobile assembly line workers in Shah Alam, Selangor. (Unpublished master thesis), Universiti Putra Malaysia. 2009.

12. Landau K, Rademacher H, Meschke H, Winter G, Schaub K, Grasmueck M, et al. Musculoskeletal disorders in assembly jobs in the automotive industry with special reference to age management aspects. Int J Ind Ergon. 2008;38(7-8):561-76.

13. Rivero LC, Rodríguez RG, Pérez MDR, Mar C, Juárez Z. Fuzzy logic and RULA method for assessing the risk of working. Procedia Manuf. 2015;3:4816-22.

14. Shi D, Zurada J, Guan J. An adaptive neuro-fuzzy inference system for predicting the risks of low back disorders due to manual material lifting jobs. Expert Syst Appl. 2013;40(14):5490-500.

15. Zurada J, Shi D, Guan J, editors. A fuzzy neural approach to classifying low back disorders risks. 2013 46th Hawaii International Conference on System Sciences; 2013: IEEE.

16. Muyeba MK, Lewis S, Han L, Keane JA, editors. Understanding low back pain using fuzzy association rule mining. 2013 IEEE International Conference on Systems, Man, and Cybernetics; 2013: IEEE.

17. Dehghani F, Zakerian SA, Zare A, Omidi F, Moradpour Z, Eynipour A, et al. Ergonomic interventions for improving working postures associated with manual materials handling (A case study of a mineral processing plant). Health Safe Work. 2016;6(4):85-94.

18. Yoon SY, Ko J, Jung MC. A model for developing job rotation schedules that eliminate sequential high workloads and minimize between-worker variability in cumulative daily workloads: Application to automotive assembly lines. Appl Ergon. 2016;55:8-15.

19. Soltanian A, Motamedzade M, Garkaz A, Mahdavi N. Persian version of Swedish occupational fatigue inventory (P-SOFI): validity and reliability. IR Occup Health. 2014;11(1).

20. Roe C, Myhre K, Marchand G, Lau B, Leivseth G, Bautz-Holter E. Measurement Properties of the Nordic Questionnaire for Psychological and Social Factors at Work: A Rasch Analysis. J Appl Meas. 2016;17(2):227-38.

21. Keshtkar A, Arzanpour S. An adaptive fuzzy logic system for residential energy management in smart grid environments. Appl Energy 2017;186:68-81.

22. Azadeh A, Fam IM, Khoshnoud M, Nikafrouz M. Design and implementation of a fuzzy expert system for performance assessment of an integrated health, safety, environment (HSE) and ergonomics system: The case of a gas refinery. Inf Sci. 2008;178(22):4280-300.

23. Padma T, Balasubramanie P. A fuzzy analytic hierarchy processing decision support system to analyze occupational menace forecasting the spawning of shoulder and neck pain. Expert Syst Appl. 2011;38(12):15303-9.

24. Gulbandilar E, Sari M, Cimbiz A. Prediction of low back pain using a fuzzy logic algorithm. Am J Biomed Sci Eng. 2015;1(5):58-62.

25. Zamanian Z, Dehghani M, Hashemi H. Outline of changes in cortisol and melatonin circadian rhythms in the security guards of Shiraz University of Medical Sciences. int J Prev Med. 2013;4(7):825. 